\title{
Tissue sparing surgery in knee reconstruction: unicompartmental (UKA), patellofemoral (PFA), UKA + PFA, bi-unicompartmental (Bi-UKA) arthroplasties
}

\author{
N. Confalonieri $\cdot$ A. Manzotti $\cdot$ F. Montironi $\cdot$ \\ C. Pullen
}

Received: 15 January 2008/ Accepted: 12 May 2008/Published online: 8 July 2008

(C) Springer-Verlag 2008

\begin{abstract}
Recently mini-invasive joint replacement has become one of the hottest topics in the orthopaedic world. However, these terms have been improperly misunderstood as a "key-hole" surgery where traditional components are implanted with shorter surgical approaches, with few benefits and several possible dangers. Small implants as unicompartmental knee prostheses, patellofemoral prostheses and bi-unicompartmental knee prostheses might represent real less invasive procedures: Tissue sparing surgery, the Italian way to minimally invasive surgery (MIS). According to their experience the authors go through this real tissue sparing surgery not limited only to a small incision, but where the surgeons can respect the physiological joint biomechanics.
\end{abstract}

Keywords Knee · Arthritis · Unicompartmental ·

Tissue sparing surgery

\section{Introduction}

In these last years a new interest in less invasive reconstructive surgery has involved the entire orthopaedic world. Minimally invasive total knee replacement is growing in popularity because of a theoretical reduced blood loss, faster recovery and reduced economical costs [1-6]. However less invasive surgery has been often identified

N. Confalonieri $(\square) \cdot$ A. Manzotti $\cdot$ F. Montironi Ist Orthopaedic Department, Centro Traumatologico ed Ortopedico (C.T.O.), I.C.P., Via Bignami 1, 20100 Milan, Italy e-mail: norbconf@tin.it

C. Pullen

Orthopaedic Department, Royal Melbourne Hospital,

Grattan Street, Parkville, VIC, Australia both by surgeons and producers as shorter surgical approaches to implant the same prostheses used with traditional approaches, performing the so called "key-hole surgery" even with new potential risks (malalignment, avulsions and local wound problems). New more conservative surgical approaches have been proposed such as quad-sparing or mid-vastus or sub-vastus [5]. These new approaches, advocated to spare skin and quadriceps tendon, could increase the possibilities to damage muscles and nerves coping with a biological contradiction. Giulio Bizzozero, an Italian biologist pioneer, already in the early years of the last century classified the tissues and the cells in three categories. He identified the "reproducible" tissues, like epithelium (skin) and endothelium, the "stable" tissues, like mesenchyma (tendons and ligaments) that recover very well, and the "noble tissues" (muscles and nerves), which should not be damaged as perpetual tissues [7].

On this purpose it has been hypothesized that real miniinvasive surgery should not be matched only with shorter incision but both with a new respect for all the tissues and with a preserved joint kinematics using new tools and smaller implants, redefine it as tissue sparing surgery [8].

Likewise despite the initial enthusiasm, more recently different Authors recommend caution towards these miniincision techniques in total joint replacement [9-13]. Dalury et al. [14] pointed out how although total knee arthroplasty performed using a minimal incision may provide some early advantages, minimal incisions can impede a surgeon's vision and may influence component alignment and possibly compromise long-term outcome.

Unicompartmental knee replacement (UKR) and patellofemoral replacement (PFR) are well-accepted surgical procedures for the treatment of knee arthritis. Furthermore, few surgeons in the world experienced association of 
different small implants matching a philosophy of real less invasive procedures.

Unluckily, despite the clear advantages of these "small implants" in terms of less invasive surgery, even in 60year-old non-obese patients with unicompartmental knee arthritis, some authors still feel TKR as the most reliable procedure [15].

The authors present their experiences together their own interpretation of less invasive surgery in knee reconstruction throughout an analysis of these "small implants" and their performance.

\section{Unicompartmental knee replacement}

The ideal indications for UKR by Kozinn and Scott [16] had been revised more recently by several authors and in association to new designs and materials have been resulted in a higher success rate. Eickmann et al. [17] in a review of 411 consecutive medial unicompartmental knee arthroplasties that had been performed between 1984 and 1998 with use of a variety of fixation techniques, polyethylene sterilization techniques, and designs, found an $80 \%$ survival rate at 9 years. Factors that were associated with revision included younger age, thinner initial polyethylene, longer polyethylene shelf age, and certain designs. O'Rourke et al. [18] reported the clinical results of 136 unicompartmental knee arthroplasties in 103 patients after a minimum duration of follow-up of 21 years. Nineteen knees (14\%) were revised during the study period because of progression of disease (nine knees), loosening (eight), or pain (two); the mean time to revision was 10.2 years. They also reported a significantly higher rate of revision in patients who had been less than 65 years of age at the time of surgery $(P=0.005)$. Recently a high survivorship, greater than $90 \%$ at 10 years follow-up, has been shown even in patients less than 60 years old by Swienckowski et al. [19].

In comparison with a TKR, UKR allows use of smaller implants, shorter operative time, preservation of both the cruciate ligaments and minimal bone resection [20, 21]. Maintenance of the anterior cruciate ligament and its mechanoreceptors may produce a better functional result in UKR [22-24]. Knee kinematics during flexion following UKR has been shown to more closely resemble the intact knee. On the other hand biomechanical studies of TKR have yielded results far from that of a normal knee [22-25].

Weale et al. [26] documented a superior functional recovery with a higher performance in descending stairs and better patient satisfaction with UKR compared with TKR. In a cadaveric study Patil et al. [27] demonstrated normal joint biomechanics after a UKR implantation in a knee.

Few studies in the literature have compared the clinical outcomes of UKR with TKR. Newman et al. [20] presented a randomized study comparing UKR to TKR showing a greater range of motion following UKR. This difference was not shown to be statistically significant using the Bristol scoring system. The authors did not however analyse the grade of patellofemoral arthritis in each group and performed a patella resurfacing in all patients in the TKR group. The degree of patellofemoral degeneration may have adversely affected the results in the UKR group. However this retrospective study was not based on patients with matched grades of arthritic change.

We performed recently a matched paired study comparing UKR to computer assisted TKR in the treatment of isolated medial femoro-tibial arthritis. In the study strict criteria were used for patient selection and matching. These criteria included bone mass index, pre-operative range of motion and grade of patellofemoral arthritis, which have not been documented in previous studies. Alignment of all the computer-assisted TKR prosthesis in this study in the frontal plane was within $4^{\circ}$ of ideal for the Hip-KneeAnkle angle reducing any influences of malalignment upon the final outcome. Both Knee Society Score and a dedicated UKR outcome score (GIUM) [28] were used to evaluate the results [29].

No statistically significant difference was seen in the post-operative Knee Society score for either group. Significant differences were seen between the two groups in the functional results and in the GIUM score. In the UKR group all patients achieved a range of motion greater than $120^{\circ}$ and could walk for longer distances. This was despite less accurate limb alignment in the UKR group. In addition to inferior results for the computer assisted TKR group the costs of the procedure were obviously greater because of the expensive implants and technology along with longer surgical times and hospital stay. A UKR in our study was estimated to be approximately at least 3,100 € cheaper with no need of blood transfusions.

However, minimally invasive techniques and computerassisted surgery have become more commonplace even in UKR procedures [21, 30]. Luring et al. [31] reported on the use of a non-imaging-based navigation system for minimally invasive unicompartmental knee arthroplasty. When compared with conventional techniques, computer-assisted navigation was associated with a significantly improved mechanical axis as well as improved alignment of the tibial and femoral components in the coronal plane (with $95 \%$ as compared with $70 \%$ of the components being aligned within $4^{\circ}$ of ideal) with an added operative time of $19 \mathrm{~min}$. Jenny et al. [32] in 2005 reviewed his experience with computer-assisted navigation and he found improved limb alignment as compared with that achieved with conventional techniques.

Despite its wide diffusion some investigators have raised concerns regarding the use of minimally invasive 
techniques in UKR. Since 2004 Howe [33] reported a risk of retained cement after UKR already with a traditional approach. Berend et al. [34] reported 20.2\% of failure at an average follow-up of 38 months using a mini-invasive technique with a correlation with a body-mass index of $>32$. Hamilton [35] found that the minimally invasive procedure was associated with higher rates of revision (11.3\% compared with $8.6 \%$ ) and aseptic loosening (3.7\% compared with $1.0 \%$ ) in standard open procedure.

A number of prosthetic designs are now available including both mobile and fixed tibial bearing surfaces. Despite this there is only another trial comparing two different UKR designs. In 2002 Emerson et al. [36] retrospectively compared 51 UKR with fixed tibial-bearings with 50 UKR with mobile-bearings. At an average follow-up of 6.8 and 7.7 years, respectively, no difference in clinical outcome was identified using the Knee Society scoring. In 2004, we presented a prospective study between mobile and fixed bearing in UKR. In this study the clinical outcome of the two groups was similar for all parameters measured. No statistically significant clinical advantage could be demonstrated between a fixed or mobile bearing tibial component in UKR at a mean follow-up of 5.7 years [28].

\section{Patellofemoral replacement}

The surgical management of patients younger than 50 years old with isolated patellofemoral arthritis is initially aimed at preserving the patellofemoral joint. Osteotomy to transfer load from lateral to medial and from distal to proximal on the patella has been described with positive results in these patients $[37,38]$. Patients with advanced arthritis including femoral trochlear disease are not good candidates for osteotomy. Patellectomy and isolated patellar resurfacing have been advocated in the past even if with both poor long-term results and potential negative effects on a future TKR [39, 40]. In literature different authors reported excellent results following total knee arthroplasty for the treatment of isolated patellofemoral arthritis in elderly patients [41-43].

Likewise young patients with advanced isolated patellofemoral arthritis, not candidates for osteotomy, patellectomy, isolated patellar resurfacing, or total knee arthroplasty still represent a challenge for the orthopaedic surgeons. The dramatic increase in use of traditional UKR with a much more conservative approach to the knee, have resulted in a rekindled interest in the concept of isolated patellofemoral arthroplasty.

Likewise patellofemoral arthroplasty is an attractive alternative to TKR with potential advantages. Ideal indication is a truly isolated patellofemoral arthritis with a varus deformity no greater than $5-6^{\circ}$ and a valgus deformity of $7-8^{\circ}$ according to Witvoet [43]. With the correct indications and surgical technique, good results can be obtained in more than $80 \%$ of patients.

Actually most of patellofemoral implants are resurfacing prostheses and only few models provide a real replacement. In 2005 the implants available have been divided by Witvoet [43] in four models:

- Models attending to reproduce closely as possible the normal patellofemoral joint. These implants have a shallow asymmetrical trochlea with a higher lateral border and a grove running downwardly and medially. The patella component is dome shaped

- Implants with a deeper but symmetrical trochlear shield.

- Prostheses with a wider angled trochlea

- Implants with a modular metal backed patellar element with a removable/fixed polyethylene insert.

The results reported in literature are quite different, however lower rate of success are reported in resurfacing and metal backed implants. Concerns in the first series reported in literature were given by a residual patellar instability often cause of secondary surgical procedures for balancing the extensor mechanism. Cartier et al. [44] in 1990 recommend a simultaneous extensor mechanism realignment and patellofemoral replacement. Furthermore, as with all unicompartmental replacements, other concerns are given by a progression of disease to the other compartments in the knee. Goodfellow et al. [45] suggests a link between medial patellofemoral facet osteoarthritic change and medial tibio-femoral unicompartmental disease.

Actually preferences should be given to implants where in case of failure the patella component could be compatible with other total joint replacement and using the same anterior femoral cut. Lubinus and Blazina et al. [46, 47] reported fair results after use of a so-called off-the-shelf design. Board et al. [48] in 2004 reported only 53\% excellent and good results in 17 patients at a follow up of only 1.5 years. In 2003 French Society of Orthopaedic Surgery (SOFCOT) Meeting a multicenter study with different implants reported 69\% of good and very good results and $20.8 \%$ had been revised with a TKR [49].

Ackroyd et al. [50] reported a 2- to 5-year follow-up study showing $90 \%$ of good and very good results shortterm results with $6 \%$ of revision to TKR. Merchant et al. [51] also recently reported favourable early results following use of a modular prosthesis for patellofemoral arthroplasty. Fourteen of 15 patients had a good or excellent result at 2.25-5.5 years postoperatively. In 2006 Sisto et al. [52] reported very promising using a custom patellofemoral implant at an average follow-up of 73 months. He obtained only excellent and good results with no 
additional surgery in 25 implants with a strong improvement compared to the traditional patellofemoral implants.

In literature there are few reports about the treatment of failed patellofemoral arthroplasty. Sisto et al. [53] in 1997 reported good results using a total knee arthroplasty. The recent development of minimally invasive surgical techniques may ultimately offer reduced morbidity when a patellofemoral prosthesis is implanted, but the need to access both the trochlear and the retropatellar surfaces without the ability to "decompress" the extensor mechanism by resection of distal, femoral, and proximal tibia bone leaves little cope for significant developments in minimally invasive access. Computer assisted alignment systems are now available even for these implants to address both the implant alignment and the patellar tracking in all the range of motion helping the surgeon in a guided soft tissue release to improve patellar tracking and tilting [54].

\section{Bi-unicompartmental knee replacement}

Bicruciate ligament retention in TKR has been evaluated since the earliest non hinged implants since the late 1960s. In gait studies by Andriacchi et al. [25] the knees in which both cruciate ligaments were retained were the only arthroplasty that had normal flexion. As well Stiehl et al. [55] demonstrated that bicruciate retaining TKR typically experienced a physiological posterior femoral roll-back during a deep knee bend with a limited anterior-posterior translation and remained posterior to the mid-saggital line in all positions.

Despite all this biomechanical studies the first results in literature were quite poor with the first designs with higher rate of failure respect the traditional implants. Lewallen et al. [56] reported in a 10 years follow-up study of polycentric TKR only $66 \%$ of survivorship.

More recently, new designs with modified surgical techniques have been introduced. Cloutier et al. [57] in 1991 reported a $96 \%$ success rate in a 9- to 11-year followup study with bicruciate-retaining implants.

However even nowadays medial and lateral tibio-femoral arthritis are traditionally seen as ideal an indication for total knee replacement even if TKR is not a perfect solution and does not result in a normal knee from a biomechanical point of view. Few surgeons around the world have been using an even less invasive implant than the above mentioned bicruciate retaining TKR since several years using two unicompartmental knee replacement to address the two tibio-femoral compartments simultaneously. The benefits of this approach when compared to TKR include greater tissue sparing, reduced surgical morbidity and easier revision surgery. In addition a recent study has demonstrated that Bi-UKR more closely resembles the biomechanics of an intact knee than a TKR [23]. Fuchs et al. [24] reported that implants preserving both the cruciate ligaments can achieve functional results at least similar to TKR without any arthritis progression. Current patient's expectations following knee replacement surgery include a knee that resembles normal and allows an unrestricted active life. Because of the superior biomechanical resemblance of the Bi-UKR to a normal knee it may better match these expectations. Despite these potential advantages no series of bi-unicompartmental knee replacement has been reported in the literature.

We have been performing bi-unicompartmental knee replacement since 1999 in very selected cases (less than 5\% of our volume of knee replacement for year) (Figs. 1, 2a-c).

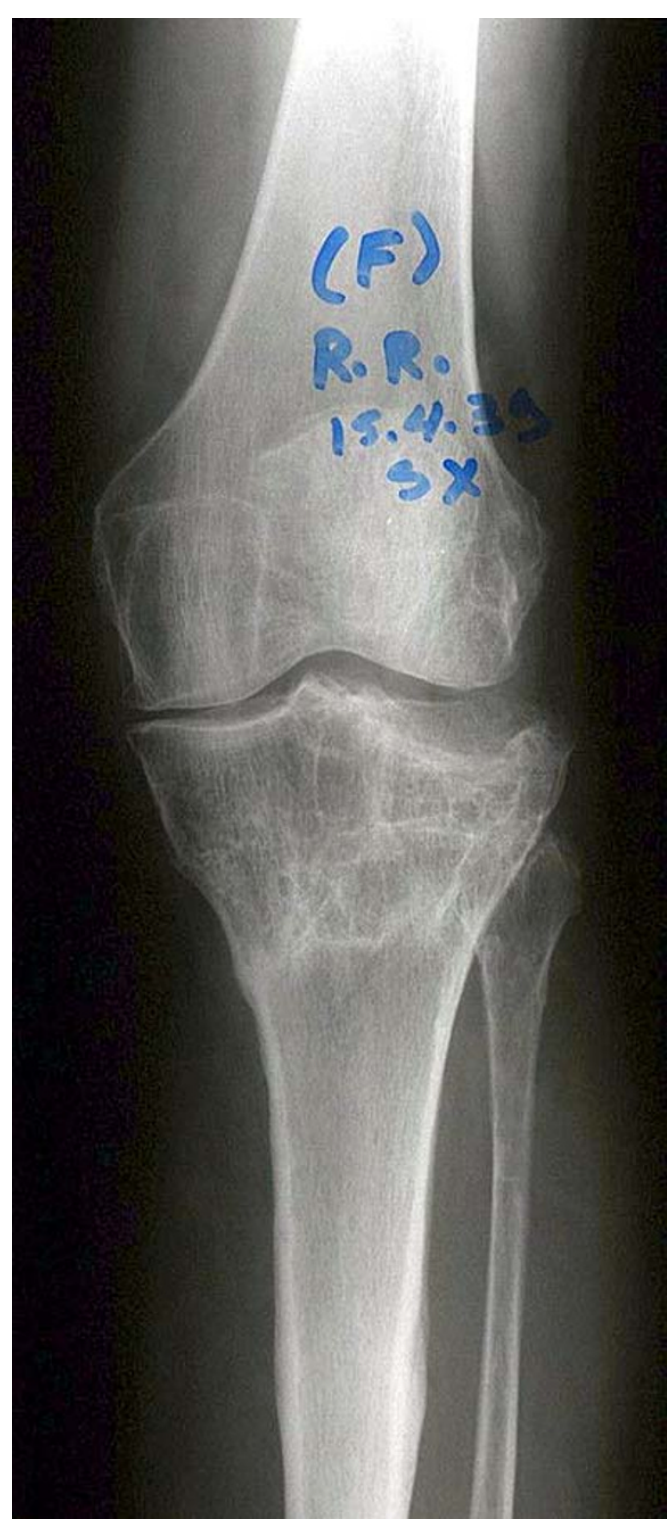

Fig. 1 a Preoperative radiographs of a patient undergoing a bi-UKR 
Fig. 2 a, b Postoperative radiographs after the implantation. c Intraoperative image of a bi-UKR
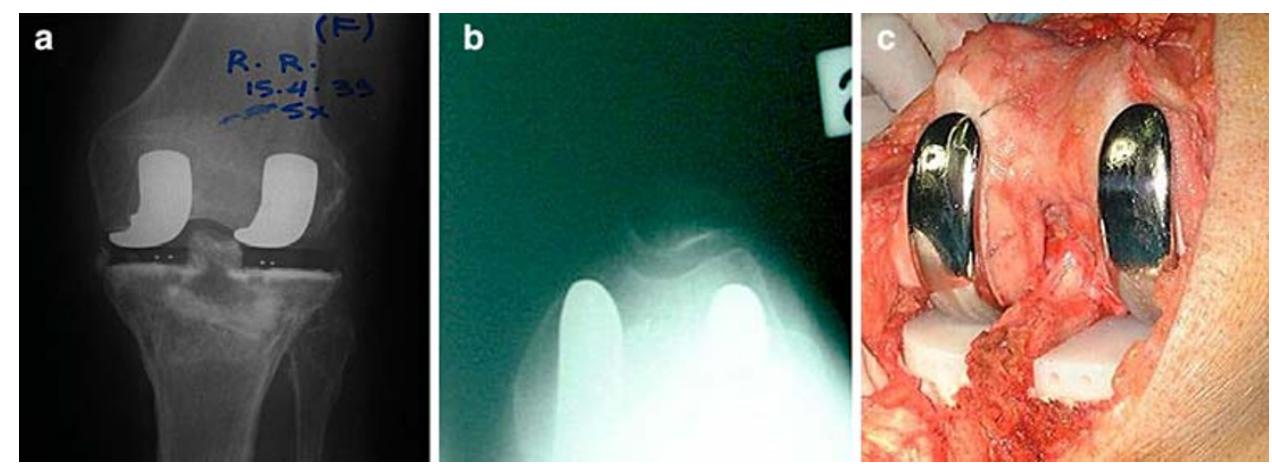

Our approach involved an approximately $12-13 \mathrm{~cm}$ midpatellar skin incision with a single anteromedial arthrotomy and lateral patella retraction. In all cases the medial UKR was performed first. This allowed for correct re-alignment of the limb by replacing the most severely diseased compartment. The amount of bone to be resected from the medial compartment of the tibia to correct the limb alignment was determined pre-operatively. This calculation was based on the amount of axial deformity and the thickness of the implanted components. The minimum tibial bone cut was given by the difference between the prosthesis thickness and the axial deviation angle [8]. For example if a patient had a varus deformity of $8^{\circ}$ and the prosthesis being used had a thickness of $11 \mathrm{~mm}$, the planned minimum medial tibial bone to be resected would be approximately $3 \mathrm{~mm}$. Using this technique the amount of bone to be resected from the lateral compartment corresponds to the thickness of the implant. In 2006 we have reviewed, at a minimum follow-up of 3 years (mean 57.8 months), our experience with these implants in 23 patients enrolled prospectively for a bi-unicompartmental knee replacement [8]. Pre-operatively patients were evaluated with both the WOMAC Osteoarthritis index and the Knee Society score. At latest follow-up the mean WOMAC score was 1.9 for pain, 0.6 for stiffness, and 4.8 for function. The mean Knee Society score was 84.6 , a mean functional score of 86.3 was recorded and a mean UKR dedicated outcome score (G.I.U.M.) was 78.1 with no abnormal results. All the patients were satisfied with the outcome and would undergo the same procedure again. No implant has required revision. The most common complication occurred intra-operatively. In three cases $(12.5 \%)$ an intra-operative fracture of the tibial spines during implantation of the prosthesis possibly related to excessive tension on the anterior cruciate ligament. All fractures were managed successfully with intraoperative internal fixation. This fracture did not adversely affect the final result. In an attempt to overcome this complication a more precise computer-assisted technique for Bi-UKR has been introduced since 2003 [58] to achieve a well balance implant both in extension and flexion and with no tension on the ACL tibial insertion.

\section{Patellofemoral and unicompartmental replacement}

The association of an unicompartmental to a patellofemoral implant is one of the hottest topics today. Leaving intact the ACL and treating simultaneously the worn patellofemoral and one of the tibio-femoral compartments may be an attractive option for the modern knee surgeon [59]. Objective of this association is to extend indications for Unis in knees with an intact ACL to preserve the normal knee biomechanics. No reports are present in literature even if different authors have been using this association since many years. Our experience is limited to 16 cases (12 for antero-medial and four for antero-lateral arthritis), all performed in the last 2 years using a computer assisted technique to assess the patella tracking and without failure up to now (Figs. 3a, b, 4a, b).

In 2007, a revolutionary bicompartmental design has been proposed specifically to address the joint involvement of these patients with a monolithic device that resurfaces both the medial and the patellofemoral compartments, while leaving the lateral bone areas and cartilage intact. No implant for the antero-lateral arthritis has been created yet. In addition to bone conservation, the anterior and posterior cruciate ligaments are preserved, resulting in more normal knee function. A minimally invasive surgical technique is well suited for this procedure and allows for a quicker recovery when compared to TKR. Treatment specifically targeted at the pathologic compartments without loss of normal bone and ligaments results in a rapid return to normal activity, increased stability, and decreased pain. In literature there is only a short-term (33 months) follow-up of 95 cases performed in a pilot-study with this new implant $[60,61]$. The authors reported no revision with a high level of satisfaction following this implant. 


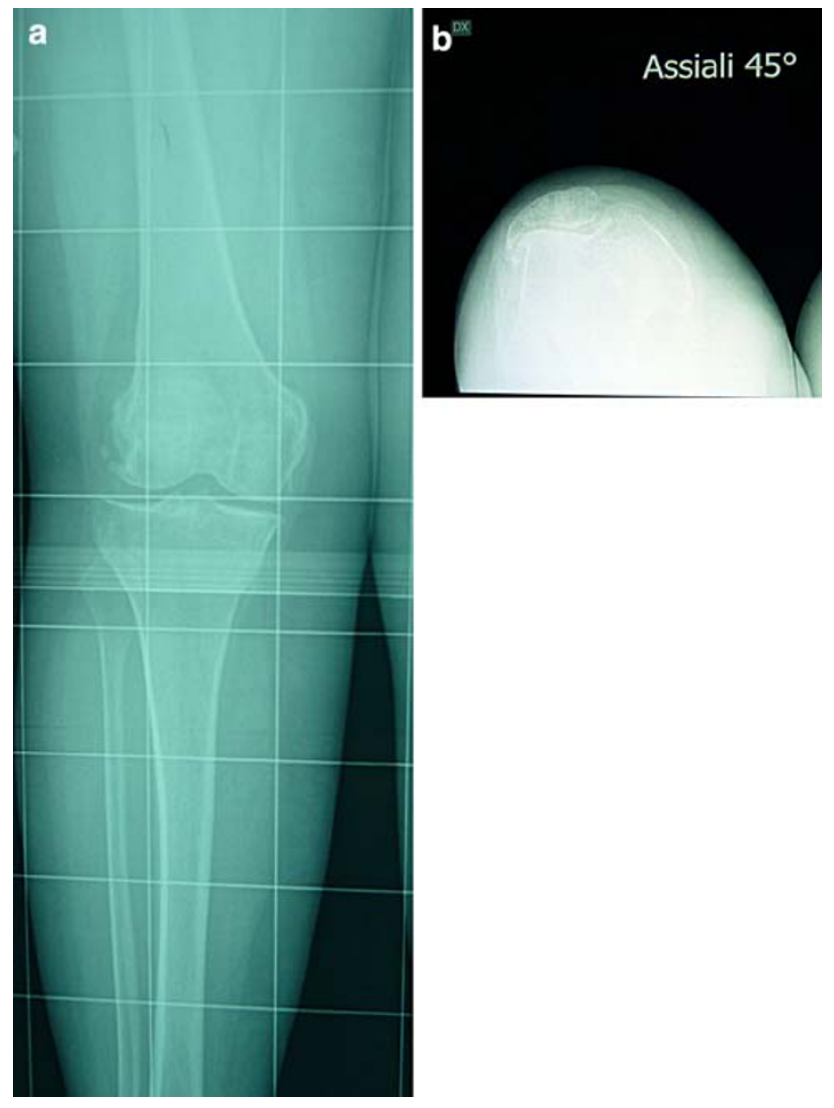

Fig. 3 a, b Preoperative radiographs of a patient undergoing a $\mathrm{PFR}+\mathrm{UKR}$
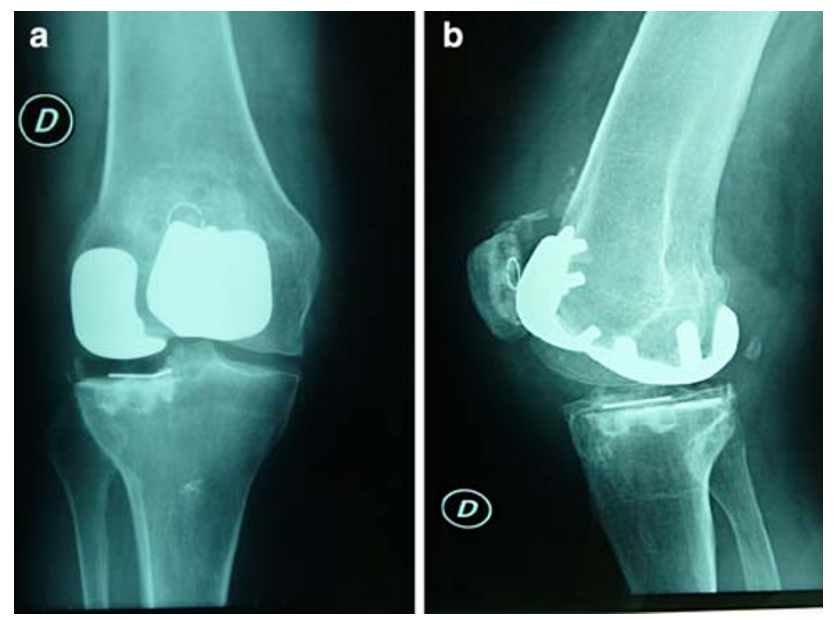

Fig. 4 a, b Postoperative radiographs after the implantation

\section{Conclusion}

The shifting demographics of patients with localized knee arthritis, including younger, more active patients, is a major impetus for growing interest in conservative surgical alternatives such as UKR and PFR.
The role of minimally invasive techniques for the treatment of knee arthritis continues to evolve towards a concept of "tissue sparing surgery". The first enthusiasm towards shorter surgical approaches has been mitigate by not permanent advantages together new complications. Small implants and a preserved joint biomechanics could represent a new development in reconstructive surgery. The authors do advocate "personalized on time treatment" for each patient according to severity of the disease using different implants option.

Conflict of interest statement The authors declare that they have no conflict of interest related to the publication of this manuscript.

\section{References}

1. Berger RA, Sanders S, Gerlinger T, Della Valle C, Jacobs JJ, Rosenberg AG (2005) Outpatient total knee arthroplasty with a minimally invasive technique. J Arthroplasty 207(suppl 3):33-38

2. Haas SB, Cook S, Beksac B (2004) Minimally invasive total knee replacement through a mini midvastus approach: a comparative study. Clin Orthop Relat Res 428:68-73

3. Laskin RS (2005) Minimally invasive total knee arthroplasty: the results justify its use. Clin Orthop Relat Res 440:54-59

4. Laskin RS (2004) Minimally invasive total knee replacement using a mini-mid vastus incision technique and results. Surg Technol Int 13:231-238

5. Lonner JH (2006) Minimally invasive approaches to total knee arthroplasty: results. Am J Orthop 35(7 suppl):27-33

6. Tenholder M, Clarke HD, Scuderi GR (2005) Minimal-incision total knee arthroplasty: the early clinical experience. Clin Orthop Relat Res 440:67-76

7. Mazzarello P, Calligaro AL, Calligaro A (2001) Giulio Bizzozero: a pioneer of cell biology. Nat Rev Mol Cell Biol 2:776-781

8. Confalonieri N, Manzotti A (2006) Tissue-sparing surgery with the bi-unicompartmental knee prosthesis: retrospective study with minimum follow-up of 36 months. J Orthopaed Traumatol 7:108112

9. Bal BS, Haltom D, Aleto T, Barrett M (2006) Early complications of primary total hip replacement performed with a twoincision minimally invasive technique. Surgical technique. J Bone Joint Surg Am 88(suppl 1 Pt 2):221-233

10. Berend KR, Lombardi AV Jr (2005) Avoiding the potential pitfalls of minimally invasive total knee surgery. Orthopedics 28(11):1326-1330

11. Mow CS, Woolson ST, Ngarmukos SG, Park EH, Lorenz HP (2005) Comparison of scars from total hip replacements done with a standard or a mini-incision. Clin Orthop Relat Res 441:80-85

12. Ogonda L, Wilson R, Archbold P, Lawlor M, Humphreys P, O'Brien S, Beverland D (2005) A minimal-incision technique in total hip arthroplasty does not improve early postoperative outcomes. A prospective, randomized, controlled trial. J Bone Joint Surg Am 87(4):701-710

13. Thornhill TS (2004) The mini-incision hip: proceed with caution. Orthopedics 27(2):193-194

14. Dalury DF, Dennis DA (2005) Mini-incision total knee arthroplasty can increase risk of component malalignment. Clin Orthop Rel Res 440:77-81

15. Pavone V, Boettner F, Fickert S, Sculco TP (2001) Total condylar knee arthoplasty: a long term follow-up. Clin Orthop 388:18-25

16. Kozinn SC, Scott R (1989) Unicondylar knee arthroplasty. J Bone Joint Surg 71A(1):145-150 
17. Eickmann TH, Collier MB, Sukezaki F, McAuley JP, Engh GA (2006) Survival of medial unicondylar arthroplasties placed by one surgeon 1984-1998. Clin Orthop Relat Res 17:167-175

18. O'Rourke MR, Gardner JJ, Callaghan JJ, Liu SS, Goetz DD, Vittetoe DA, Sullivan PM, Johnston RC (2005) The John Insall Award: unicompartmental knee replacement: a minimum twentyone-year followup, end-result study. Clin Orthop Relat Res 440:27-37

19. Swienckowski JJ, Pennington DW (2004) Unicompartmental knee arthroplasty in patients sixty years of age or younger. J Bone Joint Surg 86-A suppl 1(Pt 2):131-142

20. Newman JH, Ackroyd CE, Shah NA (2001) Unicompartmental or total knee replacement? J Bone Joint Surg 80-B:862-865

21. Repicci JA (2003) Mini-invasive knee unicompartmental arthroplasty: bone-sparing technique. Surg Technol Int 11:282

22. Banks SA, Frely BJ, Boniforti F, Reischmidt C, Romagnoli S (2005) Comparing in vivo kinematics of unicondylar and biunicondylar knee replacement. Knee Surg Sports Traumatol Arthrosc 13:551-556

23. Fuchs S, Tibesku CO, Frisse D, Genkinger M, Laaß H, Rosenbaum D (2005) Clinical and functional of uni-and bicondylar sledge prostheses. Knee Surg Sports Traumatol Arthrosc 13:197-202

24. Fuchs S, Frisse D, Tibesku CO, Genkinger M, Laaß H, Rosenbaum D (2002) Proprioceptive function, clinical results and quality of life after unicondylar sledge prostheses. Am J Phys Med Rehab 81:478-482

25. Andriacchi TP, Andersson GB, Fermier RW, Stern D, Galante JO (1980) A study of lower-limb mechanics during stair-climbing. J Bone Joint Surg Am 62(5):749-757

26. Weale AE, Halabi OA, Jones PW, White SH (2001) Perceptions of out-comes after unicompartmental and total knee replacements. Clin Orthop 382:143-153

27. Patil S, Colwell CW, Ezet KA, D'Lima DD (2005) Can normal knee kinematics be restored with unicompartmental knee replacement? J Bone Joint Surg 87A:332-338

28. Confalonieri N, Manzotti A, Pullen C (2004) Comparison of a mobile with a fixed tibial bearing unicompartmental knee prosthesis: a prospective randomized trial using a dedicated outcome score. Knee 11(5):357-362

29. Manzotti A, Confalonieri N, Pullen C (2006) Unicompartmental versus computer-assisted total knee replacement for medial compartment knee arthritis: a matched paired study. Int Orthop 31(3):315-319 (Epub 2006 Aug 2)

30. Archibeck MJ, White RE Jr (2006) What's new in adult reconstructive knee surgery. J Bone Joint Surg Am 88(7):1677-1686

31. Luring C, Bathis H, Tingart M, Perlick L, Grifka J (2006) Computer assistance in total knee replacement-a critical assessment of current health care technology. Comput Aided Surg 11(2):77-80

32. Jenny JY (2005) Navigated unicompartmental knee replacement. Orthopedics 28(10 suppl):s1263-s1267

33. Howe DJ, Taunton OD Jr, Engh GA (2004) Retained cement after unicondylar knee arthroplasty. A report of four cases. J Bone Joint Surg Am 86-A(10):2283-2286

34. Berend KR, Lombardi AV Jr, Mallory TH, Adams JB, Groseth KL (2005) Early failure of minimally invasive unicompartmental knee arthroplasty is associated with obesity. Clin Orthop Relat Res 440:60-66

35. Hamilton WG, Collier MB, Tarabee E, McAuley JP, Engh CA Jr, Engh GA (2006) Incidence and reasons for reoperation after minimally invasive unicompartmental knee arthroplasty. J Arthroplasty 21(6 suppl 2):98-107

36. Emerson RH Jr, Hansborough T, Reitman RD, Ros W, Higgins LL (2002) Comparison of a mobile with a fixed-bearing unicompartmental knee implant. Clin Orthop 404:62-70
37. Fulkerson JP (1983) Anteromedialization of the tibial tuberosity for patellofemoral malalignment. Clin Orthop Relat Res 177:176-181

38. Maquet P (1979) Mechanics and osteoarthritis of the patellofemoral joint. Clin Orthop Relat Res 144:70-73

39. Boyd HB, Hawkins BL (1948) Patellectomy. A simplified technique. Surg Gynecol Obstet 86:357-358

40. West FE (1962) End results of patellectomy. J Bone Joint Surg Am 44:1089-1108

41. McKeever DC (1955) Patellar prosthesis. J Bone Joint Surg Am 37:1074-1084

42. Pagnano MW, Clarke HD, Jacofsky DJ, Amendola A, Repicci JA (2005) Surgical treatment of the middle-aged patient with arthritic knees. Instr Course Lect 54:251-259

43. Witvoet J (2005) Should patellofemoral prostheses still be used for the treatment of isolated patellofemoral osteoarthritis? Eur Instruc Course Lect 7:174-183

44. Cartier P, Sanouillier JL, Grelsamer R (1990) Patellofemoral arthroplasty: 2 to 12 year follow-up study. J Arthroplasty 5:49-55

45. Goodfellow JW, Hungerford DS, Zindel M (1976) Patello-femoral Joint mechanism and pathology: functional anatomy of the patello-femoral joint. J Bone Joint Surg 58-Br:287-290

46. Blazina ME, Anderson LJ, Hirsh LC (1990) Patellofemoral replacement: utilizing a customized femoral groove replacement. Tech Orthop 5:53-55

47. Lubinus HH (1979) Patella glide bearing total replacement. Orthopedics 2:119-127

48. Board TN, Mahmoud A, Ryan WG, Banks AJ (2004) The lubinus patellofemoral arthroplasty: a series of 17 cases Arch Orthop Trauma Surg 124:285-287

49. Allain J, Dejour D (2004) L'arthrouse femoropatellaire isolèe. Rev Chir Orthop 90(suppl):115-119

50. Acroyd CE, Newman JH (2003) The Avon patellofemoral arthroplasty; 2 to 5 years results. J Bone Joint Surg 85-B (suppl II): $162-163$

51. Merchant AC (2004) Early results with a total patellofemoral joint replacement arthroplasty prosthesis. J Arthroplasty 19:829_ 836

52. Sisto DJ, Sarin VK (2006) Custom patellofemoral arthroplasty of the knee. J Bone Joint Surg Am 88(7):1475-1480

53. Sisto DJ, Cook DL (1997) Total knee replacement in patients with a failed patellofemoral replacement. Orthop Trans 21:115

54. Cossey AJ, Spriggins AJ (2006) Computer-assisted patellofemoral arthroplasty: a mechanism for optimizing rotation. J Arthroplasty 21(3):420-427

55. Stiehl JB, Komistek RD, Cloutier JM, Dennis DA (2000) The cruciate ligaments in total knee arthroplasty: a kinematic analysis of 2 total knee arthroplasties. J Arthroplasty 15(5):545-550

56. Lewallen DG, Bryan RS, Peterson LF (1984) Polycentric total knee arthroplasty. A ten-year follow-up study. J Bone Joint Surg Am 66(8):1211-1218

57. Cloutier JM, Sabouret P, Deghrar A (1999) Total knee arthroplasty with retention of both cruciate ligaments. A nine to elevenyear follow-up study. J Bone Joint Surg Am 81(5):697-702

58. Confalonieri N, Manzotti A (2005) Computer assisted bi-unicompartmental knee replacement. Int J Med Robot Comput Assis Surg 1(4):1-6

59. Levitan D (2006) Patellofemoral knee replacement effective when following strict indication criteria. Orthop Today Int 9:8

60. Engh GA (2007) A bicompartmental solution: what the Deuce? Orthopedics 30:770

61. Rolston L, Bresh J, Engh GA, Alois F, Kreuzer S, Nadaudad M, Puri L, Wood D (2007) Bicompartmental knee arthroplasty: a bone-sparing, ligament sparing, and minimally invasive alternative for active patients. Orthopedics 30(8 suppl):70-73 